\title{
Retahílas y canciones infantiles de procedencia europea en el exilio americano
}

\section{Retahilas and children's songs of European origin in the American exile}

\author{
María Jesús RUIZ y Graciela PELEgRíN \\ (Universidad de Cádiz / investigadora independiente) \\ majesus.ruiz@uca.es / † \\ ORCID ID: 0000-0001-6501-4559
}

\begin{abstract}
Children's memory of Spanish exile can RESUMEN: La memoria infantil del exilio español se be found in the repertoires published in America puede encontrar en los repertorios publicados en since 1939. These collections reveal various América a partir de 1939. Estas colecciones revelan processes of re-creation that occur in the migratory diversos procesos de re-creación que ocurren en el flow (sometimes back and forth) of songs and flujo migratorio (a veces de ida y vuelta) de retahílas, as well as in the overlap between popular canciones y retahílas, así como en las imbricaciones poetry and author poetry. entre poesía popular y poesía de autor.
\end{abstract}

KEYWORDS: Retahílas, children's songs, exite. PALABRAS-ClAVE: retahílas, canciones infantiles, Spanish Civil War, memory

exilio, Guerra civil española, memoria

¿El destierro congela la memoria? La memoria infantil queda congelada en nuestro primer exilio, el de la infancia. El desgarro de ser arrancado de la propia tierra y la angustia por que la memoria no disipe el propio ser late detrás de toda la actividad editorial del exilio español del 39. Quizás late especialmente en la frondosa parcela de libros para niños, continuadores esforzados de la revolución pedagógica ocurrida en España en las primeras décadas del siglo XX, revolución que no llegó a ser (decapitada por la Guerra Civil y la posterior dictadura) y que intentó continuarse para otros niños, los niños americanos de Cuba, México, Argentina, Puerto Rico...

Los libros infantiles del exilio se reparten en varias vertientes, todas ellas continuadoras de las nuevas líneas pedagógicas que se habían trazado en España al calor del krausismo (PMR y LIJEM): adaptaciones de clásicos, teatro, poemarios de autor, libros escolares de aprendizaje musical y recopilaciones de la tradición oral. La mayoría de estas obras proponen, en mayor o menor medida y siguiendo distintas estrategias, ofrecer a los niños una dosis de su memoria cultural, vacunarlos contra el olvido, conscientes siempre de que la felicidad e integridad del futuro adulto depende en buena parte de que sea capaz de reconocerse en una memoria colectiva, la suya (Ruiz, 2010).

Nuestra propuesta pasa por revisar una parte de esa actividad editorial, concretamente la de los libros que son recopilación de la lírica infantil española anterior a 1939, a los que el forzado exilio obligó a difundirse en tierras americanas. Tomamos como corpus y punto de partida el catálogo elaborado por Ana Pelegrín en Pequeña memoria recobrada (PMR), y manejamos la propia biblioteca de Ana, reunida 
pacientemente a lo largo de casi treinta años en librerías de viejos de México, Cuba, Argentina y España. Esta es la selección.

\begin{tabular}{|c|c|c|}
\hline Referencia bibliográfica & $\begin{array}{l}\text { N. en el } \\
\text { catálogo } \\
\text { de PMR }\end{array}$ & $\begin{array}{l}\text { Clasificación en } \\
\text { PMR }\end{array}$ \\
\hline $\begin{array}{l}\text { Melcior Font (recopilador), Cançoner de Nadal, ilustrado por } \\
\text { Rafael Barradas, Barcelona, Juventud, } 1935\end{array}$ & 32 & Edad de Plata \\
\hline $\begin{array}{l}\text { Elena Fortún y María Rodrigo (recopiladoras), Canciones } \\
\text { infantiles, ilustrado por Gori Muñoz, Madrid, Aguilar, 1934? }\end{array}$ & 33 & Edad de Plata \\
\hline $\begin{array}{l}\text { Juan Gutiérrez Gili (recopilador), Canciones de Navidad, } \\
\text { ilustrado por Rafael Barradas, Barcelona, Juventud, 1926? }\end{array}$ & 37 & Edad de Plata \\
\hline $\begin{array}{l}\text { Eduardo Martínez Torner, Canciones populares españolas } \\
\text { armonizadas para coro, Barcelona, Bellas Artes, Consejo } \\
\text { Central de Música, } 1938\end{array}$ & 42 & Edad de Plata \\
\hline $\begin{array}{l}\text { Eduardo Martínez Torner, Cancionero musical, Madrid, } \\
\text { Instituto Escuela, } 1928 \text { y Londres: Bradford / Dickens, Drayton } \\
\text { House, } 1947\end{array}$ & 43 у 203 & $\begin{array}{l}\text { Edad de Plata y } \\
\text { Exilio }\end{array}$ \\
\hline $\begin{array}{l}\text { Gonzalo Menéndez Pidal (selección y notas), Romancero, } \\
\text { Madrid, Instituto Escuela, } 1936\end{array}$ & 44 & Edad de Plata \\
\hline $\begin{array}{l}\text { Ramón Menéndez Pidal (selección y notas), Flor nueva de } \\
\text { romances viejos, Buenos Aires, Espasa Calpe, } 1938\end{array}$ & 45 & Edad de Plata \\
\hline $\begin{array}{l}\text { José Luis Sánchez Trincado y R. Olivares Figueroa, Poesía } \\
\text { infantil recitable, ilustrado por C. Edelhoff, Madrid, Aguilar, } \\
1936\end{array}$ & 52 & Edad de Plata \\
\hline $\begin{array}{l}\text { Carlos María de Vallejo, Los maderos de San Juan. Glosario } \\
\text { de rondas y canciones infantiles. Ilustrado por Méndez } \\
\text { Magariños, Cádiz, } 1932 \text { y Montevideo, Biblioteca Alfar, } 1943\end{array}$ & 55 y 285 & $\begin{array}{l}\text { Edad de Plata y } \\
\text { Exilio }\end{array}$ \\
\hline $\begin{array}{l}\text { Jesús Bal y Gay, Romances y villancicos españoles del siglo } \\
\text { XVI (edición moderna para canto y piano), México, La Casa } \\
\text { de España, FCE, } 1939\end{array}$ & 101 & Exilio \\
\hline $\begin{array}{l}\text { Francisco Giner de los Ríos (selección), Tesoro de romances } \\
\text { españoles, México, Nuestro Pueblo, } 1940\end{array}$ & 176 & Exilio \\
\hline $\begin{array}{l}\text { Benjamín Jarnés (dirección literaria) y Luis Doporto (dirección } \\
\text { artística), El libro de oro de los niños. Un mundo maravilloso } \\
\text { para la infancia, ilustrado por Alma Tapia et al., Buenos Aires, } \\
\text { UTEHA, } 1943 \text { y México, Acrópolis-UTEHA, } 1951\end{array}$ & $\begin{array}{ll}184 & \mathrm{y} \\
186 & \end{array}$ & Exilio \\
\hline $\begin{array}{l}\text { Eduardo M. Torner, El folklore en la escuela, Buenos aires, } \\
\text { Losada, 1946, } 1960 \text { y } 1965\end{array}$ & $\begin{array}{ll}201 \\
202 \\
204\end{array}$ & Exilio \\
\hline Concha Méndez, Villancicos de Navidad, México, Rueca, 1944 & 211 & Exilio \\
\hline $\begin{array}{l}\text { José Moreno Villa, Lo que sabía mi loro, ilustrado por José } \\
\text { Moreno Villa, México, Isla, } 1945\end{array}$ & 215 & Exilio \\
\hline $\begin{array}{l}\text { José Moreno Villa, Navidad, villancicos, posadas, Ilustrado } \\
\text { por José Moreno Villa, México, Isla, } 1945\end{array}$ & 217 & Exilio \\
\hline $\begin{array}{l}\text { Ana Pelegrín (selección y prólogo), Poesía española para } \\
\text { niños, Madrid, Taurus, } 1969\end{array}$ & 243 & Exilio \\
\hline $\begin{array}{l}\text { Emilio Pita, Cantigas de nenos, Rosario, Edición de Arayl, } \\
1944\end{array}$ & 249 & Exilio \\
\hline $\begin{array}{l}\text { Juan Miguel Roma, Selección de Poesía para niños, Valencia, } \\
\text { Ares, } 1961\end{array}$ & 259 & Exilio \\
\hline
\end{tabular}




\begin{tabular}{|l|l|l|}
\hline $\begin{array}{l}\text { Luis Santullano, La poesía del pueblo. Romances y canciones } \\
\text { de España y América, Buenos Aires, Librería Hachette, 1955 }\end{array}$ & 263 & Exilio \\
\hline $\begin{array}{l}\text { Arturo Serrano Plaja (selección y prólogo), Hijo del alba. } \\
\text { Villancicos, canciones, ensaladillas y coloquios pastoriles de } \\
\text { Nochebuena, Buenos Aires, Imp. López, 1943 }\end{array}$ & Exilio \\
\hline $\begin{array}{l}\text { Rodolfo Halffter, Cancionero musical popular español, } \\
\text { México, Ateneo Español, 1939 y 1990 }\end{array}$ & $\begin{array}{l}\text { Exilio } \\
\text { Retornos de lo } \\
\text { vivo lejano }\end{array}$ \\
\hline $\begin{array}{l}\text { José Moreno Villa, Vida de un hombre flaco, México, } \\
\text { Universidad Autónoma de México, 1998 }\end{array}$ & $\begin{array}{l}\text { Exilio } \\
\text { Retornos de lo } \\
\text { vivo lejano }\end{array}$ \\
\hline
\end{tabular}

A la hora de explicar el intenso trasvase de la tradición oral española a América por vía impresa hay que atender a varios factores:

1. Hay un flujo histórico, que naturalmente arranca de todo ese acarreo de gentes, de pliegos y de libros que marca la relación de España con América desde el siglo XVI. Flujo de ida y vuelta, como sabemos, que se deja apreciar acentuado en las primeras décadas del XX, en casos, por ejemplo, como el de la obra de Carlos María de Vallejo, Los maderos de San Juan, publicada primero en Cádiz, en 1932, como compilación de la memoria infantil uruguaya del autor, y luego en Montevideo en 1943, como compilación de la memoria española que el niño uruguayo tiene como herencia.

2. Resulta igual de importante, o más, la intensa actividad de intelectuales en torno a la tradición oral infantil desde el siglo XIX, generaciones sucesivas que hunden su razón de ser en el pensamiento romántico, en el volkgeist, y que desde las investigaciones de Demófilo y sus colaboradores en las Sociedades de Folklore hasta la Generación del 27 recopilan, reelaboran, usan como materia prima, como principio y meta de su creación, la tradición oral (Sánchez Ortiz, 2013).

3. Común a todas estas generaciones es la consideración que los autores tienen de sí mismos: se piensan, antes que creadores, re-creadores, eslabones de una cadena ininterrumpida que los coloca en el deber de ser puente entre el pasado y el futuro. Toman al pie de la letra la sentencia de Juan de Mairena («En nuestra literatura, todo lo que no es folklore es pedantería») y llegan a considerar que la gran justificación de su tarea es «devolver al pueblo lo que es del pueblo», consigna que fundamenta toda la actividad artística y educativa de las Misiones Pedagógicas, en la que muchos de los futuros exiliados se implican. Proverbial al respecto es la figura de Alejandro Casona — «trabajo sobre el cañamazo de la tradición»-, que escribe su teatro popular del exilio nutriéndose siempre de la tradición oral española (Ruiz, 2008 y 2009).

4. Finalmente, entendemos que es el propio destierro, la necesidad provocada por este de mantener vínculos con lo más íntimamente emocional de la tierra perdida, lo que definitivamente espolea la producción y la difusión impresa de estas recopilaciones.

Las colecciones de lírica infantil de la Edad de Plata (1920-1936), nutridas - y nutrientes - de las vanguardias artísticas europeas, marcan una radical renovación literaria en las lecturas infantiles, «representada por las canciones y el teatro de García Lorca, de Rafael Alberti, de Concha Méndez; los cuentos surrealistas de María Teresa 
León; los Títeres de Pinocho de Salvador Bartolozzi y Magda Donato y la serie de cuentos de Celia, el personaje de Elena Fortún» (Pelegrín, 2008: 13). En estos libros están ya diseñados los caminos que recorrerá la tradición oral infantil española en el exilio:

- Siguiendo la pauta marcada por las canciones de Lorca, hay primero una representación importante de textos de autor basados en la recreación de lo popular, tal es el caso de los Villancicos de Navidad de Concha Méndez (1944) o de las Cantigas de nenos de Emilio Pita (1944). Esta última colección, en gallego, apunta asimismo una tendencia significativa del exilio, la del nacionalismo idiomático, al que los exiliados se ven obligados a renunciar por el Régimen represor impuesto en España a partir de 1939.

- Las Canciones de Navidad de Gutiérrez Gili (1926) o la lírica en catalán (más nacionalismo idiomático) del Cançoner de Nadal de Melcior Font (1935) son. ya no textos de autor, sino recopilaciones surgidas del trabajo de campo, del aprecio, por tanto, de la propia memoria popular como documento cultural y poético. Qué duda cabe que colecciones como estas impulsarán, en la lejanía americana, la obra de José Moreno Villa (Navidad, villancicos, pastorelas, posadas, piñatas, 1945) o la de Arturo Serrano Plaja, (Hijo del alba, villancicos, canciones, ensaladillas, 1943).

- La vocación pedagógica esencial de la Edad de Plata alienta el rescate del cancionero popular del Siglo de Oro, presente por ejemplo en la Poesía infantil recitable de José Luis Sánchez Trincado y R. Olivares Figueroa (1936); una vocación que en el destierro explica trabajos como el de de Jesús Bal y Gay, Romances y villancicos españoles del siglo XVI. Edición moderna para canto y piano (1939).

- En su labor de armonizador de melodías populares - que le llevaría a ser Director del Coro del Pueblo de las Misiones Pedagógicas-, Eduardo Martínez Torner publica su Cancionero musical (1928), que se reeditaría en Londres en 1947. Dice en sus palabras preliminares: «Las canciones reunidas en este volumen han sido seleccionadas de varias colecciones, publicadas o inéditas, atendiendo exclusivamente a su belleza melódica». Importante es anotar la clasificación por zonas y comarcas para las «canciones populares actuales» (Santander, Burgos, Valladolid, Zamora, La Mancha, Ávila, Andalucía, Extremadura...), reconocimiento de la diversidad folklórica de una España que nunca fue «Una» y cuyo testigo recoge, ya en el exilio mexicano, el Cancionero musical popular español (1939) de Rodolfo Halffter.

- Finalmente, la época de la Edad de Plata deja entrever cuán frondosa pudo ser - y no llegó a ser- la recolección de la tradición oral infantil española en unos momentos en los que aún el mundo poético de los niños no había sido arrasado por los medios de comunicación de masas y las nuevas tecnologías. De este modo, los riquísimos y prometedores repertorios compilados por Elena Fortún y María Rodrigo para sus Canciones infantiles (1934) o por Carlos María de Vallejo en Los maderos de San Juan (1932) hubieron de resignarse, en tierras americanas, a ejercicios de memoria como el de Juan Miguel Roma (Selección de poesía para niños, 1961) o el de José Moreno Villa (Lo que sabía mi loro, 1945). 
Abordamos ahora una revisión de algunas de estas últimas recopilaciones citadas con un objetivo: apreciar en lo posible las repercusiones que el trasvase de la memoria cultural europea pudo tener en sus nuevos destinos americanos.

La colección de Elena Fortún y María Rodrigo ofrece una clasificación muy particular que habla del interés de las recopiladoras no solo por dejar testimonio del texto infantil, sino también por analizarlo, por apreciar los diversos niveles de tradicionalización que este repertorio registra y, en definitiva, por determinar las coordenadas singulares en las que se recrea el cancionero de los niños. Tras los apartados de «Romances y romancillos de los siglos XVI y XVII» y «Romances de ciego», agrupan en torno al título de «Viejas canciones» versiones de Quisiera ser tan alta, Arroyo claro o El patio de mi casa. Revelando un especial esfuerzo por determinar el origen de los textos, en el apartado de «Canciones adaptadas del francés» incluyen Mambrú y Santa Catalina. Hay asimismo un interés también por fijar la antigüedad de los textos, los niveles de la tradición: en el apartado de «Siglos XVII y XIX» incluyen Las hijas de Merino o El vestido nuevo. Tras la catalogación, pues, palpita un análisis o, al menos, una intuición - que no deja de sorprendernos en fechas tan tempranas- que reconoce el repertorio infantil como singular frente a otros ámbitos de la tradición oral y, en tal sentido, integrador de fórmulas muy diversas (romances, canciones y retahílas), por lo que se incluyen incluso invocaciones como ¡Que llueva!

El caso de Los maderos de San Juan de Carlos María de Vallejo deja apreciar, por su parte, interesantes aspectos de la migración de textos tradicionales infantiles entre España y América.

El Cádiz de 1925 vio llegar a Carlos María de Vallejo, al que el Atlántico trajo para ocupar el cargo de cónsul de Uruguay. Vallejo llega a una ciudad de secular tradición americanista que - en palabras de su entonces alcalde, Cayetano del Toro- acaba de demoler sus murallas «para permitir que el progreso llegue desde el mar» (Oslé, 1991: 18). Cádiz, en esos momentos, es una ciudad turbada por la moda modernista, verdadera secta de poetas, que proliferan en tertulias y en veladas poético-musicales en las que la literatura empieza a entenderse como el mejor revulsivo para acabar con una sociedad caduca e inmóvil (Ruiz, 2016). Vallejo, que a su llegada a Cádiz ya había publicado varios libros, no tarda en sumarse a estos ambientes lúdicos y poéticos, haciendo de su consulado y de su casa un centro neurálgico de la nueva bohemia, algo que a los menos modernos y más escépticos y desconfiados como José María Pemán les haría exclamar: «El cenáculo de Vallejo era decididamente loco y apayasado» (Hernández Guerrero, 1979).

En Cádiz y en 1932 publica Vallejo la primera edición de Los maderos de San Juan, glosario de rondas y canciones infantiles. El libro, compilación de la tradición poético-musical de los niños españoles y uruguayos, se inscribe en esa pedagogía renovadora, y revolucionaria, que la dictadura no dejó cuajar. Como otros tantos intentos similares, Los maderos de San Juan propone un aprendizaje de la memoria cultural por medio de la propia memoria y se salta, así, caducos métodos de enseñanza escolar. El repertorio recopilado suma 31 textos a los que su autor anota así en el colofón:

Este libro, undécimo de su autor, fue escrito en Montevideo (Uruguay), sin más elementos de juicio para su estructuración lírica y folklórica que las canciones y rondas trasladadas a América por España, recogidas de memoria en los corros y juegos infantiles, que se conservan por tradición, hasta el presente, en aquellas tierras.

Con la excepción de un viaje largo a su tierra natal, Carlos María de Vallejo permaneció en Cádiz al menos hasta bien entrada la década de los treinta. En Cádiz fundó 
y dirigió un periódico, Renovación, y proyectó publicar (sin llegar a hacerlo) un libro de viajes, Piel de toro. Los maderos de San Juan, como otros tantos libros de su estirpe, ni se difundió por las escuelas ni prosperó en las editoriales y solo en Montevideo, una década después, volvió a publicarse. La edición uruguaya (de 1943) añade treinta textos al repertorio de la edición española. Su autor lo explica así:

Este libro, undécimo del autor, escrito en Montevideo (Uruguay), se publicó por primera vez en la ciudad de Cádiz el año 1932, con treinta y una composiciones líricas, nueve estilizaciones musicales y seis ilustraciones artísticas, a base de las canciones y rondas recogidas en la tradición oral que persisten en los corros y juegos infantiles, enriquecido posteriormente en España en la forma que presenta esta nueva edición.

El caso de Los maderos de San Juan evidencia —como antes decíamos - algunas de las transformaciones que pueden producirse en el trasvase de una memoria cultural a otro territorio. Vallejo transcribe, primero, su memoria de Uruguay, una memoria que reconoce procedente de España y, luego, en la edición uruguaya, amplia y matiza esa memoria a través del repertorio con el que se pone en contacto durante su estancia en Cádiz. Hay que tener en cuenta, además, que su actividad intelectual en España entre 1925 y 1932 está marcada por la creación poética vanguardista, esencialmente por el postismo (Palacios, 2001), y ese factor impulsa a Vallejo a «intervenir» con la propia creación poética en los textos tradicionales recopilados. Para apreciarlo, baste el cotejo de las versiones de La pájara pinta publicadas respectivamente en 1932 y 1943, en las que resulta evidente (marcamos los versos en cursiva) la intervención de una «mano culta» que sigue, no obstante, el ritmo y la idea de la canción popular.

Versión de 1925:

Echadita la pájara pinta a la sombra del verde limón, con las alas cortaba las hojas, con el pico cortaba la flor.

— ¡Ay! ¡ay! / cuándo veré mi amor, ¡ay! ¡ay! / cuándo lo veré yo.

Echadita la pájara pinta a la sombra del verde limón, me repite su arrullo constante, que por mí late su corazón.

—Ay! ¡ay! / cuándo veré mi amor, — ¡ay! ¡ay! / cuándo lo veré yo.

Echadita la pájara pinta a la sombra del verde limón, su rosado piquito me dice que me quieres con honda pasión.

—Ay! ¡ay! / cuándo veré mi amor, — ¡ay! ¡ay! / cuándo lo veré yo. 
Se ha escapado la pájara pinta de la sombra del verde limón, en sus alas te lleva un mensaje, $\mathrm{y}$ en el pico te lleva una flor.

—Ay! ¡ay! / pronto veré mi amor, —AAy! ¡ay! / pronto lo veré yo.

Versión de 1943:

Echadita la pájara pinta a la sombra del verde limón, con las alas cortaba las hojas, con el pico cortaba la flor.

— ¡Ay! ¡ay! / cuándo veré mi amor, ¡ay! ¡ay! / cuándo lo veré yo.

Echadita la pájara pinta a la sombra del verde limón, con su arrullo constante acelera los latidos de mi corazón.

—Ay! ¡ay! / cuándo veré mi amor, — ¡Ay! ¡ay! / cuándo lo veré yo.

Echadita la pájara pinta a la sombra del verde limón, su rosado piquito me dice que me quieres con honda pasión.

—Ay! ¡ay! / cuándo veré mi amor, —Ay! ¡ay! / cuándo lo veré yo.

Se ha escapado la pájara pinta de la sombra del verde limón, en sus alas te lleva un mensaje, $\mathrm{y}$ en el pico te lleva una flor.

— $A y ! ~ ; a y ! /$ pronto veré mi amor, —AA! ¡ay! / pronto lo veré yo.

Muchos de los repertorios infantiles del exilio evidencian su voluntad de mantenerse al margen de la escuela, o mejor dicho de la antigua escuela, de esa pedagogía obsoleta e inútil con la que pretende acabar el ideario krausista (Díaz Marcos, 2004). Es el caso de la obra de Eduardo M. Torner. Anota Torner en su libro El folklore en la escuela: «los romances, los cuentos, las leyendas hacen vivir al niño, transportado en alas de su portentosa imaginación, todo un mundo poético» y recomienda un material «excluido hasta ahora de la escuela, tal vez solo por inadvertencia de su utilidad práctica». Lo más llamativo - y trascendente- de la obra de Torner es su anti-pedagogía, o su nueva pedagogía. En sus planteamientos se evidencian los principios krausistas de las 
Misiones Pedagógicas, las consignas educativas de Manuel Bartolomé Cossío, quien prefería llamar a su proyecto «Misiones anti-pedagógicas» (García-Velasco, 2006). Torner concentra los textos de lírica infantil en los apartados de juegos (el columpio, la comba, el corro, juegos para correr, sedentarios, escénicos...) y danzas (las palmadas, las palomitas, de arcos). Ante tal criterio, hay que entender varios principios implícitos:

- La finalidad del aprendizaje es la felicidad del individuo (llevar la felicidad a través del arte)

- El texto tradicional infantil es un compendio de manifestaciones lúdico-artísticas, es un etnotexto muy completo: comprende palabra, música, gesto, ritual de socialización... y lleva al niño no solo a memorizar y cantar, sino a cumplir una de las necesidades primordiales del ser humano: la escenificación, el teatro.

Parece incuestionable que las mismas convicciones pedagógicas que animan a Torner están en la obra de José Moreno Villa, Lo que sabía mi loro; sobre todo la intimidad entre la memoria, la música y el juego. De la revisión minuciosa que Sánchez Ortiz (2013) hace de esta joya del folklore infantil nos gustaría destacar:

- Las ilustraciones y algunas partituras, testimonio de ese espíritu de expresión-arte integral que perseguía el krausismo

- La libertad a la hora de re-crear los textos infantiles desde una perspectiva infantil, gráfica y textual

- La incorporación de la propia infancia

- La incorporación del auca (aleluyas) al repertorio re-creativo de los niños

Por otra parte, José Moreno Villa y Carlos María de Vallejo recrean la tradición, a veces, sin reparos, sintiéndose parte natural de la cadena transmisora. Tras sus libros late la actitud de Menéndez Pidal cuando afronta la redacción de su Flor nueva de romances viejos (1938):

El que compare los textos... sentirá extrañeza ante otras variantes que le son totalmente desconocidas; la mayoría de estas proceden de textos antiguos ignorados por los críticos antedichos, o de nuevas versiones modernas obtenidas de la tradición oral; algunas son de mi propia inventiva. Al introducir esas variantes creo que no hago sino seguir los mismos procedimientos tradicionales por los que se han elaborado todos los textos conocidos... Todo recitador, antiguo o moderno, retoca y refunde el romance que canta. La tradición, como todo lo que vive, se transforma de continuo; vivir es variar.

La obra de Rodolfo Halffter transparenta toda el alma romántica, la devoción por el volkgeist y la fe en la natur poesie. Halffter publica su Cancionero musical popular español nada más llegar a México, donde arriba a principios del verano de 1939. Dice en su nota preliminar:

Existe una música natural, no reglamentada por lo circunstancial y erudito, a través de la cual cada pueblo expresa los sentimientos que le afectan o conmueven: dolores, esperanzas, sufrimientos, alegrías... La música natural, para su origen mismo, es esencialmente popular, porque es reflejo del alma de un pueblo o de una raza. 
Insiste luego en dos aspectos: la intención de que todas las regiones folklóricas españolas queden representadas; y la fidelidad en la transcripción (musical y textual) del documento folklórico. Como observa Ángel Cosmos (editor de 1990), en Halffter domina la vertiente de compositor y armonizador; no hace propiamente un cancionero infantil, sino que selecciona aquellas muestras que «ofrecen gracia». Incluye hermosas coplas de corro de Madrid y coplas de columpio de Málaga.

Vivir es variar. Al hilo del cotejo de algunas colecciones de lírica infantil posterior al exilio, como la maravillosa Naranja dulce, limón partido, nos atrevemos a una hipótesis. Creemos que la difusión impresa en América de la lírica infantil española colocó a esta en un contexto re-creador muy particular, diferente al español, menos sujeto a la tradición libresca y escolar, más libre, con más capacidad re-creadora, más atrevido a la hora de reinventar, de fundir, de imaginar, más rico en la consecución de variantes inesperadas, más intergenérico. Lo demuestran los textos de Naranja dulce, limón partido y los atrevimientos de Moreno Villa en Lo que sabía mi loro. Quizás la lírica infantil del exilio encontró en el exilio lo que describe María Zambrano: "Yo no concibo mi vida sin el exilio, ha sido como mi patria, o como una dimensión de una patria desconocida, pero que una vez que se conoce, es irrenunciable». El destierro, pues, no congela la memoria.

\section{BIBLIOGRAFÍA}

DíAz MARCos, Ana M. (2004): "NNadie entre que sepa geometría": pedagogía y regeneración en el teatro de Casona», en Actas del Homenaje a Alejandro Casona (1903-1965). Congreso Internacional en el centenario de su nacimiento (Universidad de Oviedo, 5-8 de noviembre de 2003), A. Fernández Insuela, M. ${ }^{a}$ del C. Alfonso García, M. ${ }^{a}$ Crespo Iglesias, M. ${ }^{a}$ Martínez-Cachero Rojo y M. Ramos Corrada (eds.), Oviedo, Fundación Universidad de Oviedo, Ediciones Nobel, pp. 83-92.

Díaz Roig, Mercedes y Miaja De La PeÑA, M. ${ }^{a}$ Teresa (1979): Naranja dulce, limón partido. Antología de la lírica infantil mexicana, México, El Colegio de México.

García-Velasco, José (2006): «Una cultura de la felicidad. Cossío y las Misiones Pedagógicas», en Las Misiones Pedagógicas. 1931-1936, Catálogo de la Exposición celebrada en el Centro Cultural Conde-Duque de Madrid, preparada por Eugenio Otero Urtaza, Madrid, Sociedad Estatal de Conmemoraciones Culturales-Residencia de Estudiantes, pp. 131-157.

HERnÁNDEZ GuERRERO, José Antonio (1979): «Datos para la historia de las letras gaditanas (1900-1930)», Gades: Revista del Colegio Universitario de Filosofía y Letras, 2, pp. 135-154.

LIJEM = La literatura infantil y juvenil española en el exilio mexicano, 2013, Pedro C. Cerrillo y María Teresa Miaja (coords.), México, El Colegio de San Luís / Ediciones de la Universidad de Castilla La Mancha.

Oslé, Julián (1991): Cádiz 1900 en las fotografías de Ramón Muñoz, Madrid, Silex.

PALACIOS, Amador (2001): «Una meditación desde el postismo», en Carlos Edmundo de Ory. Textos críticos sobre su obra, Jaume Pont y Jesús Fernández Palacios (eds.), Cádiz, Servicio de Publicaciones de la Diputación Provincial, pp. 175-185.

PELEGRín, Ana (2008): «Una aproximación a los libros infantiles en el exilio español (1939-1977)», en Pequeña memoria recobrada. Libros infantiles del exilio del 39, 
Ana Pelegrín, María Victoria Sotomayor y Alberto Urdiales (eds.), Madrid, Ministerio de Educación, Política Social y Deporte, pp. 13-42.

$\mathrm{PMR}=$ Pequeña memoria recobrada. Libros infantiles del exilio del 39,2008, Ana Pelegrín, María Victoria Sotomayor y Alberto Urdiales (eds.), Madrid, Ministerio de Educación, Política Social y Deporte.

RuIZ, María Jesús (2008): «De Sanabria a Buenos Aires: el destierro escénico de Alejandro Casona», en Pequeña memoria recobrada. Libros infantiles del exilio del 39, Ana Pelegrín, María Victoria Sotomayor y Alberto Urdiales (eds.), Madrid, Ministerio de Educación, Política Social y Deporte, pp. 119-129.

RuIZ, María Jesús (2009): «Exilio y melancolía del teatro popular de Alejandro Casona», en Exilio y Artes Escénicas / Arte Eszenikoak Erbestean, Iñaki Beti Sáez y Mari Karmen Gil Fombellida (eds.), Donosita-San Sebastián, Editorial Saturrarán / Hamaika Bide / Universidad de Deusto, pp. 157-175.

RuIZ, María Jesús (2010): «La maleta de Josefina: una colección de lecturas de los niños de la guerra de España en la Unión Soviética», en Tradición y modernidad de la literatura oral. Pedro C. Cerrillo y César Sánchez Ortiz (eds.), Cuenca, Universidad de Castilla-La Mancha, pp. 279-295.

RuIz, María Jesús (2016): «Vallejo contra Pemán», Revista digital CaoCultura. URL: <http://caocultura.com/vallejo-contra-peman/>

SÁNCHEZ ORTIZ, César (2013): «Educación, cancionero y exilio: literatura infantil oral en la obra de Moreno Villa», en Presencia del cancionero popular infantil en la lírica hispánica. Homenaje a Margit Frenk. Pedro C. Cerrillo y César Sánchez Ortiz (coords.), Cuenca, Universidad de Castilla-La Mancha, pp. 373-383.

Fecha de recepción: 24 de abril de 2019

Fecha de aceptación: 4 de septiembre de 2019

$$
9
$$

